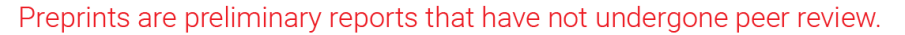 They should not be considered conclusive, used to inform clinical practice, or referenced by the media as validated information. \\ Agriculturally Intensified Landscapes Are Associated With Reduced Body Condition of Lady Beetles
}

\section{Julia Tiede ( $\nabla$ tiedej@uni-muenster.de )}

University of Münster https://orcid.org/0000-0003-0037-8559

\section{Benjamin Iuliano}

University of Wisconsin-Madison

Claudio Gratton

University of Wisconsin-Madison

\section{Research Article}

Keywords: conservation physiology, natural enemies, body condition, entomology, agroecology, land-use

Posted Date: January 3rd, 2022

DOI: https://doi.org/10.21203/rs.3.rs-1158990/v1

License: (1) (i) This work is licensed under a Creative Commons Attribution 4.0 International License.

Read Full License 


\title{
1 Agriculturally intensified landscapes are associated with reduced 2 body condition of lady beetles
}

\author{
3 Julia TIEDE* \\ 4 Institute for Evolution and Biodiversity, University of Münster, \\ 5 Hüfferstrasse 1, 48149, Münster, Germany \\ 6 *Corresponding author: tiedej@uni-muenster.de, (49) 2518324672 \\ 7 ORCID: 0000-0003-0037-8559 \\ 9 Benjamin IULIANO \\ 10 Department of Integrative Biology, University of Wisconsin-Madison, \\ 11 Wisconsin Energy Institute \\ 121552 University Ave, Madison, WI 53726 USA \\ 13 ORCID: 0000-0002-9348-5363 \\ 15 Claudio GRATTON \\ 16 Department of Entomology, University of Wisconsin-Madison \\ 17 Madison, Wisconsin 53706 USA \\ 18 ORCID: 0000-0001-6262-9670
}

19

\section{ACKNOWLEDGEMENTS}

21 We would like to thank the landowners who allowed us to sample lady beetles on their land, and we also

22 thank Rachel Mallinger, Hannah Gaines-Day, Heidi Liere, Allison Dehnel, and Ken Frost for rides to the

23 sampling sites. This research was supported by the United States Department of Agriculture (USDA) grants 24 2011-67009-30022 and 2018-67013-28060 to CG. 
ABSTRACT

26 Context: Agricultural intensification is contributing to a global species decline. Underlying mechanisms include toxic effects of pesticides on non-target organisms and reductions in habitat and food availability. However, the effects of agricultural intensification on body condition, particularly of ecosystem serviceproviding arthropods, are poorly understood.

Objectives: Here, we investigated whether variations in the body condition of common lady beetle species (Coleoptera: Coccinellidae) can be explained by the composition and configuration of the surrounding landscape. Assuming strong seasonal variation in food availability in intensively farmed regions, we included the entire period of lady beetle activity in our study.

Methods: Lady beetles were collected from April to September 2011 in 30 landscapes in southern Wisconsin, USA. We examined how body size, body density, and lipid content of the beetles responded to the percentage of intensive cropland, habitat diversity, and edge density in the surrounding landscape.

Results: The strongest predictor of body condition was the percentage of intensive cropland. For every $10 \%$ increase in cropland, body density decreased by about $3.9 \%$ and fat content by $6.4 \%$. Landscape diversity and edge density correlated with body condition of individual species.

Conclusions: In agriculturally intensified landscapes, lady beetles with reduced body condition may

41 produce fewer offspring, have lower survival rates, and exert less effective pest control. Thus, our results

42 suggest a mechanistic link between landscape patterns and observed declines in lady beetle populations.

43 Our results also show that the expansion of monocultures affects even common cropland-associated species

44 such as Harmonia axyridis, suggesting a long-term decline in biocontrol services in simplified agricultural 45 landscapes.

\section{KEYWORDS}

47 conservation physiology, natural enemies, body condition, entomology, agroecology, land-use 


\section{INTRODUCTION}

49 Landscape structure affects species' abilities to move, survive, and persist in their environments (Fahrig

50 2007; Tscharntke et al. 2012; Gámez-Virués et al. 2015; Martin et al. 2019; Seibold et al. 2019). This is

51 consequential not only for the conservation of biodiversity generally, but also the maintenance of service-

52 providing organisms such as pollinators and natural enemies of crop pests. Agricultural landscape simplification including loss of semi-natural habitat and reduction of crop diversity is often found to have a negative effect on the abundance and diversity of natural enemies and the biological control services they provide (Chaplin-Kramer et al. 2011; Liere et al. 2015; Rusch et al. 2016; Dainese et al. 2019). However, the count data on natural enemy abundance collected in most studies usually cover only one or a few growing seasons (but see Lamb et al. 2019) and cannot adequately capture population trajectories. This may result in incomplete or misleading conclusions about the effects of landscape structure on species responses in the long-term (Kuussaari et al. 2009). The integration of landscape ecology with conservation physiology constitutes a promising direction for resolving such limitations and advancing from pattern- to

61 process-based understanding of species and service distributions (Ellis et al. 2012; Cooke et al. 2013).

Physiological indicators of individual body condition and fitness can offer valuable insights into the status of animal populations in disturbed landscapes before a numerical response is observed. For example, stress biomarkers in birds (Latimer et al. 2020) and limb malformation in amphibians (Guerra and Aráoz 2016) respond to agricultural landscape composition and configuration. For arthropods, characteristics such as body size, mass, and lipid content are important indicators of body condition. Larger individuals are more likely to be better competitors for resources and mates, as well as have higher fecundity and reproductive success (Kajita and Evans 2010; Vargas et al. 2013a; Beukeboom 2018). While body size of holometabolous insects is determined by feeding conditions at the larval stage (Hodek 1973; Vargas et al. 2012), body mass is modulated by food availability to adults and is thought to reflect actual nutrient storage (Knapp and Knappová 2013). Lipid content is an important measure of energy reserves, which determine the ability of individuals to survive during periods of resource scarcity (Arrese and Soulages 
2009). Direct measurements of body composition, such as lipid content, also tend to be better indicators of body condition than proxy indices such as body size (Knapp and Knappová 2013; Wilder et al. 2016).

Relatively few studies have investigated the consequences of landscape structure on arthropod body condition. Early studies showed that the body size and fecundity of a generalist ground beetle was positively correlated with field perimeter-to-area ratio and percentage of perennial crops across cereal farms (Bommarco et al. 1998, Östman et al. 2001). Effects of landscape structure on body condition have also been demonstrated for wolf spiders (Öberg 2009; Drapela et al. 2013) and dung beetles (Salomão et al. 2018). Flying organisms are highly mobile and thus may be most susceptible to landscape-related drivers. While there is also a growing literature base examining the effects of landscape on body condition of wild and managed pollinators (Renauld et al. 2016; Alaux et al. 2017; Grab et al. 2019; Dolezal et al. 2019; Mogren et al. 2020), surprisingly little is known about the consequences for flying predators.

Lady beetles (Coleoptera: Coccinellidae) are highly mobile predators that provide valuable biological control services in agricultural landscapes (Obrycki et al. 2009). Despite their association with crops, population sizes are often reduced in regions that are dominated by intensive agriculture (Gardiner et al. 2009a, b; Grez et al. 2014; Woltz and Landis 2014). Tiede et al. (2017) showed that the gut microbiome of native and introduced lady beetle species in Wisconsin (USA) varied by species, prey diversity, local habitat type, and landscape context. They also found that landscape context mediated the effect of gut microbiota on beetle lipid content, but the study's relatively small sample size and qualitative measurement of lipid content makes it difficult to draw strong conclusions and left other aspects of body condition unexplored.

Here we ask whether variation in lady beetle body condition can be explained by features of the surrounding landscape. Specifically, we investigated how body size, body density, and lipid content responded to variation in landscape composition (percentage of intensive cropland, landscape diversity) and configuration (edge density) in agricultural landscapes. In a mensurative field experiment (Hadley \& Betts 2016), we sampled populations of five lady beetle species at 30 sites along a gradient from low to high agricultural intensification in southern Wisconsin, USA. The sampling period extended from beetle 
emergence from hibernation in May to September when they allocate energy for hibernation, thus including

100 periods when the region's large-scale row crops (corn and soybeans) are not yet present or are already

101 harvested, and thus do not provide food resources. We assumed that lady beetles in agriculturally intensified

102 landscapes - characterized by a high percentage of row crops, a low diversity of habitat types, and a low

103 density of habitat edges - have less access to food resources than conspecifics in more complex landscapes,

104 especially in the early and late seasons. We therefore predicted that lady beetles sampled in landscapes with

105 high agricultural intensification will have a reduced body condition compared to beetles collected in less

106 intensified landscapes. Because different lady beetle species have different habitat preferences and food

107 requirements (Lundgren and Wiedenmann 2004; Berkvens et al. 2008; Gardiner et al. 2009a; Diepenbrock

108 and Finke 2013), we also expected species-specific differences in the strength of response and relative 109 importance of different landscape factors.

\section{METHODS}

\section{Sampling locations \& collection}

112 Adult lady beetles were sampled in 30 locations in Wisconsin, USA, between April and September 2011

113 (Fig. 1). The beetles were collected opportunistically based on the phenology of local vegetation and the

114 abundance of food resources. In the early growing season when lady beetles emerged from hibernation,

115 beetles were collected by sweep netting and hand collection in alfalfa fields, grasslands, and field margins.

116 In June beetles were collected in small grain crops (wheat, oats, rye), and from late June onwards in corn

117 and soybean fields. In addition, yellow sticky traps (Great Lakes IPM GL-3310-00, Vestaburg, MI, USA)

118 were placed in semi-natural habitats such as hedgerows for 48 hours in June. The sampling method had no

119 effect on body condition metrics (data not shown) and therefore was not addressed in the statistical analysis.

120 In total we collected individuals of five aphidophagous lady beetle species (Table 1). Beetles were placed

121 in a cooler to limit their activity during transport to the lab, where they were preserved at $-20{ }^{\circ} \mathrm{C}$. 
123 Beetles were sexed and dissected under a stereoscopic microscope (10-40x magnification). The presence 124 of mite or fungus parasites was documented in 153 individuals (11.9\% of samples). Excluding these 125 specimens did not qualitatively change the results (data not shown), so we present results based on the 126 analysis of all samples. Additionally, 92 beetles (7.7\% of the samples) had soft and pale elytra and were 127 recorded as teneral (newly hatched). The presence or absence of eggs was also noted for female beetles.

128 We assessed the body condition of beetles by analyzing body size, body density, and lipid content.

129 As an indicator of structural body size, we measured elytra length and pronotum width to the nearest 0.001 $130 \mathrm{~mm}$ (ProgRes camera and CapturePro imaging system, JenOptik, Jena, Germany) and multiplied them. The 131 use of multiple size measurements has been shown to be more informative of body condition than single 132 size measurements (Knapp and Knappová 2013). In preparation for the measurement of lipid content, the 133 elytra, wings, head and pronotum were removed from the torso (thorax and abdomen) and processed 134 separately. All samples were dried at $50^{\circ} \mathrm{C}$ for 72 hours and cooled to room temperature in a desiccator for 135 at least 1 hour before being weighed to the nearest $0.001 \mathrm{mg}$ (Mettler Toledo MT5, Mettler-Toledo, 136 Columbus, OH, USA) (Anderson 1981). The torso was weighed separately from the other body parts, and 137 the values were added to obtain the total dry mass. Body mass was corrected for individual size to 138 standardize body condition, as the two measures are closely correlated (Knapp and Knappová 2013). We 139 divided mass by size to determine "body density" (i.e., size-corrected dry mass).

140 Lipid content was determined gravimetrically by the difference in dry mass before and after total 141 lipid extraction (Plaistow and Siva-Jothy 1996; Östman et al. 2001; Östman 2005). Only the torso was used 142 (pronotum and abdomen without wings, elytra and legs) as wings and elytra contain no measurable amount 143 of fat, and no metabolically usable fat is stored in the head (Plaistow and Siva-Jothy 1996). As a lipid 144 solvent, $1 \mathrm{~mL}$ of dichloromethane-methanol solution (2:1) was added to the torso in individual glass vials. 145 After 72 hours at room temperature, the lipid-containing solution was discarded, and the torso was washed 146 in another $1 \mathrm{ml}$ of dichloromethane-methanol solution for $10 \mathrm{~min}$ and dried for 72 hours at $50^{\circ} \mathrm{C}$ before re147 weighing. Percentage lipid content was calculated by dividing the lipid-free dry weight by the total dry 
weight of the torso and multiplying by 100 (Morita et al. 1999). Lipid content data was collected for all

149 species except Coccinella septempunctata. Although there were significant correlations between body 150 condition metrics (especially size and density), sufficient variation existed to test the effects of landscape 151 on each metric separately (see Online Supplement 1 Figure S1).

\section{Landscape metrics}

153 All landscape analyses were conducted at a $1 \mathrm{~km}$ radius around sampling sites. Landscape features within 154 a $0.5 \mathrm{~km}$ to $2 \mathrm{~km}$ radius have been ecologically most informative for population-level numerical responses 155 of lady beetles in previous studies (Gardiner et al. 2009a; Woltz and Landis 2014; Yang et al. 2018). While 156 lady beetles migrate between habitats and patches during the season to find ephemeral prey, foraging within 157 a patch is characterized by short-distance movements (Hodek et al. 1993; Evans 2003; Schellhorn et al. 158 2014). We therefore assume that a rather local scale is most relevant for physiological effects at the 159 individual level.

160 We used the 2011 USDA Cropland Data Layer (CDL, NASS 2011) and the landscape metrics 161 package in $\mathrm{R}$ (Hesselbarth et al. 2019) to obtain measures of landscape composition and configuration at a 162 resolution of $30 \mathrm{~m}$. We calculated the percentage of land categorized as corn and soybean, the dominant 163 crops in the region, as a metric of intensively-managed annual monoculture (hereafter "intensive 164 cropland"). Intensive cropland was negatively correlated (Pearson's $r=-0.91, \mathrm{p}<0.001$ ) with semi-natural 165 habitat (grassland and woodland classes) and was used in our analysis because this type of habitat is easier 166 to categorize unambiguously than semi-natural habitats.

167 Landscape diversity was quantified as the diversity of land cover classes using Simpson's diversity 168 index (Simpson 1949), which is less sensitive to rare classes than other metrics such as Shannon's diversity 169 index (McGarigal 1995). Edge density was calculated as the length of the habitat boundaries of all land 170 cover classes. Pearson correlation coefficients between pairs of these three landscape metrics used in our 171 analysis were $r<0.4$ (see Online Supplement 1 Figure S2 for Pearson's correlation coefficient distributions 172 of landscape metrics). 
174 We used R (v4.0.5; R Core Team 2020), and RStudio (v1.4.1103; RStudio Team 2020) for all statistical 175 analysis and the ggplot2 package (Wickham 2016) for the visualization of results. Data and code are 176 provided (Online Supplement 2).

177 We tested the effects of landscape metrics on the body condition of lady beetles with linear mixed178 effects models (lme function, nlme package; Pinheiro et al. 2021). For each combination of body condition 179 measurements (body size, body density, and lipid content) and landscape metrics (percentage of intensive 180 response variable combinations.

For each response variable, we tested whether the data fitted a normal or lognormal distribution using the fitdistrplus package (function fitdist; Delignette-Muller and Dutang 2015) in combination with Akaikés information criterion (AIC). In addition, we visually checked the error distribution of the models to verify whether a ln-transformation reduced heteroskedasticity compared to untransformed response variables. Body size data was analyzed untransformed, while body density and lipid content data were $\ln$ -

187 transformed. For models with body density as a response variable, teneral beetles (newly emerged adults) 188 were excluded since they were significantly lighter than non-teneral beetles (data not shown). In models of 189 body size or lipid content teneral beetles were statistically indistinguishable and were thus included (data 190 not shown).

191 In all models the explanatory variables were beetle species, collection date and their interactions 192 with the landscape metrics as fixed effects, and species, sex, and sampling site as nested random intercepts 193 to account for repeated measures and beetle-specific responses. In the body density and lipid content 194 models, a quadratic term was used for the collection date (allowing for a peak in mid-season), as this 195 improved model fitting (lower AICc values; http://christoph-scherber.de/stepAICc.txt). A variance function 196 with different estimates for each species was also used to account for variance heterogeneity between 197 species. 
199 effects of landscape variables and their interactions with lady beetle species on body condition metrics.

200 Weighted effects coding is an alternative to conventional "dummy coding" of categorical variables in 201 regression analysis and is well-suited to analyzing unbalanced observational data. In weighted effects 202 coding, the effect of each category (here, beetle species) represents the deviation of that category from the 203 sample mean (te Grotenhuis et al. 2017). This allowed us to test whether there is an overall effect of each 204 landscape variable on the body condition of all beetles sampled, as well as whether there are species for 205 which the relationship between body condition and landscape metric is statistically different from the 206 overall trend. The significance of all predictor terms in the linear mixed-effects models was assessed at $\alpha=$ 2070.05 using type II Wald chi-square tests (Anova function, car package; Fox and Weisberg 2018). These tests follow the principle of marginality, where each term is tested after all others, but ignores each term's 209 interactions.

A graphical overview of all effects of landscape predictors and body condition metrics of all

211 individual lady beetle species (Fig. 2) was generated based on regression coefficients calculated with the 212 generic summary function of $\mathrm{R}$ that is based on t-statistic using type-III sums of squares. The significance 213 of predictor terms did not differ from the ones determined by Wald chi-square tests. Because the scales of 214 different landscape and body condition metrics varied considerably, we standardized the regression 215 coefficients by transforming the predictor (\% intensive cropland, Simpson's diversity index, and edge 216 density) and response variables (body size, body density, and lipid content) to z-scores. Regression 217 coefficients are thus displayed in units of standard deviations.

218 For four beetle species with sufficient numbers of non-teneral female individuals for statistical 219 analysis (C. maculata, $\mathrm{n}=83 ;$ C. munda, $\mathrm{n}=32$; C. septempunctata, $\mathrm{n}=51 ; H$. axyridis, $\mathrm{n}=247$ ) we 220 examined the relationship between body condition metrics and the presence of eggs. To do this, we used 221 logistic regression models using the glmmTMB package (Brooks et al. 2017). Models included egg 222 presence/absence (1/0) as a response variable and one of the body condition metrics (body size, body 223 density, and lipid content), collection date and their interactions with species as fixed effects, and sampling 
224 location as a random intercept. We used the weighted effects coding described above to determine the 225 overall effect of body density on egg presence and possible interactions with the species. The significance 226 of predictor terms was assessed using Wald chi-square tests (Anova function, car package; Fox and 227 Weisberg 2018) as described above.

\section{RESULTS}

229 All three landscape predictors studied had a significant effect on the body condition of at least one lady 230 beetle species (Table 2; Fig. 2, 3). As the percentage of intensively managed cropland in a landscape 231 increased there was a small, but significant decrease in body density and lipid content of lady beetles. For 232 every $10 \%$ increase in landscape area covered by intensively managed cropland, there was an approximately $2333.9 \%$ decrease in beetle body density and 6.4\% decrease in beetle fat content (Table 2; Figure 2a, b). At the 234 species level, body density of two introduced species, the multicolored asian lady beetle Harmonia axyridis 235 (Fig. 2; orange dots) and the variegated lady beetle Hippodamia variegata (Fig. 2, blue dots) and fat content 236 of $H$. axyridis were significantly negatively influenced by an increasing amount of intensively managed 237 cropland. Landscape diversity and edge density did not have an overall effect for any of the body condition 238 metrics (Table 2) but had effects on individual species. The native pink spotted lady beetle 239 Coleomegilla maculata (Fig. 2; green points) had reduced fat content in more diverse landscapes. Finally, 240 C. maculata and $H$. variegata collected from landscapes with higher edge density had greater body density. 241 See Online Supplement 1 Table S1 for summary statistics on deviations of species-specific responses from 242 the overall effect for all combinations of landscape predictors and body condition metrics.

243 Lady beetle species was a strong and significant predictor of body condition in all models (Table 244 2). That is, there were inherent differences among species after accounting for landscape metrics. For 245 collection date, a quadratic term was used in the body density and lipid content models to account for the 246 higher body density and higher lipid content in mid-season. The collection date itself had an effect on body 247 density, with higher body density in the middle of the season. The interaction between collection date and 
beetle species was a significant predictor of body density and fat content (Table 2), indicating that these body condition metrics increased in some species and decreased in others over the season.

In all four species analyzed, female beetles with greater body density were more likely to have developing eggs (Online Supplement 1 Fig S3, Table S2, S3). This suggests that body density (i.e., 252 standardized body mass) is a meaningful index of fecundity. No relationship was found between the 253 presence of eggs and body size or lipid content (Online Supplement 1 Table S2, S3).

\section{DISCUSSION}

255 Landscape composition and configuration explained small but significant portions of the variation in the 256 body condition of multiple lady beetle species across southern Wisconsin's agricultural landscapes. Lady 257 beetles were generally lighter and leaner in simplified agricultural landscapes dominated by annual row crop fields. Previous studies have shown that coccinellid abundance and biological control services decline in simplified landscapes in the midwestern United States and other regions of the world (Gardiner et al. 2009b; Grez et al. 2014; Woltz and Landis 2014; Yang et al. 2018, 2019). Our results provide a possible mechanistic link for the observed relationship between landscape structure and lady beetle numeric response, and consequently ecosystem services.

Likely reasons for the effects of landscape composition and configuration on lady beetle body condition include differences in spatial and temporal resource continuity and quality. Corn and soybean 265 fields can be heavily colonized by aphids and thus provide abundant prey for lady beetles, but this is only 266 the case during limited time periods; over long periods such fields are characterized by resource scarcity, 267 e.g., before crop emergence, after crop maturity, or after pesticide application (Rand et al. 2006; Schellhorn 268 et al. 2014; Iuliano and Gratton 2020). In landscapes that are strongly dominated by a few crop 269 monocultures, these periods are synchronized over large areas and habitat patches with alternative food 270 sources are often far away and only accessible at high energetic costs (Bonte et al. 2012; Stowe et al. 2021b). 271 In contrast, in more heterogeneous landscapes where a variety of annual and perennial crops are grown and natural or semi-natural habitat patches are available, landscape complementation (in the sense of Dunning 
et al. 1992) for mobile natural enemies may occur. Landscapes with more intensive cropland may also mean greater risk of pesticide exposure (Meehan et al. 2011), which has potential lethal and sublethal consequences for lady beetles and other beneficial insects (Santos et al. 2017, Stuligross and Williams et al. 2021), though little is known about pesticide effects at the landscape scale (Mancini et al. 2020).

Landscape structure also shapes the diversity and composition of plants and arthropods (Jonsen and Fahrig 1997; Clough et al. 2007; Seibold et al. 2019; Le Provost et al. 2021) and consequently the quality of food resources for lady beetles, which in turn may influence their performance. Nutritional studies conducted in the laboratory have shown that growth rate, body composition, and fecundity can vary significantly depending on the prey and non-prey foods consumed. For example, C. maculata can complete its life cycle entirely on corn pollen, but then achieved a lower body weight and laid fewer eggs than conspecifics that feed on aphids (Lundgren and Wiedenmann 2004). In H. axyridis, known primarily as aphid predators, a diet of Lepidoptera eggs (Ephestia kuehniella Zeller) resulted in higher body weight, fat content, reproductive output, and longevity compared to a diet of pea aphids (Acyrthosiphon pisum Harris) (Specty et al. 2003; Berkvens et al. 2008). In this context, it appears to be species-specific which food types are best suited for predators to achieve high body condition. However, a mixed diet of complementary foods has been shown to be beneficial for several generalist predators and is actively sought by them (Soares et al. 2004; Raubenheimer et al. 2007; Harwood et al. 2009; Marques et al. 2015; Stowe et al. 2021a). As such, landscapes with fewer diversity of crops or landscape diversity may manifest as decreases in the physiological condition of mobile predatory arthropods such as lady beetles, leading to longer-term population declines, as has been found for other beneficial insects (Hemberger et al. 2021).

Generalist natural enemies are likely to achieve a balanced diet more easily in landscapes with high resource diversity. Locally high plant diversity and habitat heterogeneity increased the dietary diversity and composition of generalist predatory ground arthropods (Tiede et al. 2016; Staudacher et al. 2018; Macé et al. 2019). In a study from Germany and Switzerland, H. axyridis and another common aphid predator, the lacewing Chrysoperla carnea (Stephens), supplemented their diets throughout the season with pollen that, even in agriculture-dominated landscapes, came largely from non-crop plants (Bertrand et al. 2019). Local 
semi-natural habitats can supplement the food supply for natural enemies of plant pests, but the availability

300 of resources also depends on the surrounding landscape. Seibold et al. (2019) demonstrated a decline in

301 arthropods over nine years in grasslands that was particularly pronounced when the areas were embedded

302 in intensively farmed landscapes.

303 In our study, we examined the correlation of three different aspects of landscape simplification with

304 three different characteristics of coccinellid body condition. The two measures of landscape composition,

305 the percentage of predominant annual monocultures of soybean and corn, and landscape diversity were not

306 correlated. This means that a landscape with few soybean and corn crops is not necessarily a landscape with

307 many different other habitat types, and vice versa. The third metric, edge density, is a measure of landscape

308 configuration and provides information about the size of fields and other habitats. Its independence from

309 the other two landscape metrics implies that, for example, landscapes with a high percentage of intensively

310 used farmland may consist of many small fields with correspondingly high edge density, and high edge

311 density is not necessarily associated with high diversity of habitat types (see also Martin et al. 2019).

312 Of these three factors, the percentage of intensive cropland was the strongest predictor of lady

313 beetle body condition and the only one for which a general effect on all species was found. A high

314 percentage of intensive cropland was generally negatively correlated with lipid content and body density

315 of coccinellids. In a former study, lady beetles collected from semi-natural habitats had qualitatively higher

316 lipid content than conspecifics from monocultures, but a direct effect of the amount of intensive cropland

317 in the surrounding landscape could not be demonstrated (Tiede et al. 2017). The survey period of our present

318 study exceeds that of the former one by far, and thus covers a larger part of the activity period of

319 coccinellids, ranging from awakening from hibernation to reproduction of (multiple) new generations to

320 preparation for overwintering. This includes periods when annual row crops may be productive food

321 sources for natural enemies, as well as periods when crop pests are not yet or no longer present. While high

322 pest abundance can have a positive short-term effect on the development of natural enemy populations

323 (Rand et al. 2006), our results suggest longer-term negative consequences of agricultural intensification for

324 beneficial insect populations. 
While the percentage of soybean and corn fields can be easily and unambiguously categorized, landscape diversity as a measure of heterogeneity is less straightforward, as the composition of habitat types can vary greatly even with the same level of diversity. Some habitat types, although contributing to greater diversity at the landscape level, may not provide many resources for coccinellids, e.g., impervious surfaces, water bodies, or intensively pesticide-treated crops. In addition, preferences for cultivated plants or seminatural habitats are often species-specific for coccinellids. For example, native species are often found in grasslands, whereas forests play a more important role for introduced species (Gardiner et al. 2009a;

332 Werling et al. 2011; Diepenbrock and Finke 2013). Species-specific preferences may also have contributed 333 to the absence of a general effect of landscape diversity in our study. We detected a significant negative 334 effect of landscape diversity on lipid content only for the native $C$. maculata. For this species, higher population densities have previously been found in low-diversity landscapes with abundant grasslands and corn. However, overall coccinellid abundance and biological control performance were supported by high landscape diversity (Gardiner et al. 2009a; Gardiner et al. 2010). (CDL, NASS 2011) provides a relatively coarse $30 \mathrm{~m}$ x $30 \mathrm{~m}$ resolution of land cover classes. A finer341 grained landscape analysis that also captures small edge structures and habitat islands, as well as field 342 margins between the same habitat types could potentially reveal stronger impacts of edge density on 343 coccinellid performance. Small-scale structures that can be accessed with minimal energy expenditure such 344 as field margins can be an attractive source of food and shelter for coccinellids (Hodek et al. 2012). Recent 345 studies have found that edge density increases abundance of many pollinators and natural enemy species, 346 improves pollination and pest control, and increases yields in arable landscapes (Martin et al. 2019). 347 Alternatively, other measures of landscape configuration such as connectivity may reveal additional 348 landscape features that translate to physiological outcomes for lady beetles (Koh et al. 2013).

We used three different physiological parameters to estimate body condition in lady beetles to 350 account for the fact that an animal's phenotype is a consequence of many integrated and interdependent 
traits (Wilder et al. 2016). Body density and lipid content were more informative for the influence of

352 landscape structure on body condition than body size. This is of little surprise given that body size is determined during larval development (Vargas et al. 2013b). Lady beetle individuals often migrate multiple times over longer distances after hatching in search of suitable food, egg-laying or overwintering sites (Hodek et al. 1993; Schellhorn et al. 2014). The landscape at a $1 \mathrm{~km}$ radius around collection sites is thus most likely not representative of the larval feeding habitat that could have primarily influenced body size. Body density and lipid content are better predictors of recent access to resources. Lipid content is a direct measure of body composition and a good estimate of energy reserves in arthropods (Lease and Wolf 2011;

359 Knapp and Knappová 2013). Body density, calculated as size-corrected body weight, also comprises total lipid weight, but in addition includes the content of other body substances, e.g., protein. Protein is not directly related to the energy reserves of individuals but has been shown to be of considerable importance for insect reproductive fitness (Knapp and Knappová 2013; Wilder et al. 2016). Consistently, body density was also the only body parameter we measured that was correlated with the presence of eggs. We conclude that, taken together, the chosen parameters provide good insight into the effects of landscape simplification on the body condition and fitness of coccinellids. collection site that previously had high lady beetle abundance was devoid of lady beetles on the next visit. In the resulting dataset, landscape structure and collection date are somewhat confounded. As such, for species that could only be collected at a limited subset of sites or dates, the full extent of landscape effects

371 on body metrics may not have been fully measured. In addition, samples were dominated by the native 372 C. maculata and the introduced $H$. axyridis, while other species comprised $<20 \%$ of the specimens. 373 However, this is consistent with species distributions in agricultural landscapes of the upper Midwestern 374 United States (Werling et al. 2011; Lamb et al. 2019). The dramatic decline of native coccinellid species in 375 the United States, (Harmon et al. 2007; Gardiner et al. 2011; Lamb et al. 2019), Europe (Brown and Roy 376 2018) and South America (Grez et al. 2013, 2014) since the late 20th century has often been linked to the 
377 introduction of invasive competitors such as $H$. axyridis, but an important mediating effect of landscape

378 structure has also been emphasized (Gardiner et al. 2009a, 2011; Werling et al. 2011; Grez et al. 2013;

379 Bahlai et al. 2015). Our results demonstrate that even highly mobile species closely associated with

380 cropland and pest control, such as $H$. axyridis, exhibit the effects of agricultural intensification on 381 physiological performance.

382 While the landscape effects on lady beetle body condition documented here are modest, they 383 suggest the potential loss of biological pest control due to a yet-to-be fully realized numerical response, 384 since lighter and leaner beetles may be less effective predators, produce fewer offspring and have a lower 385 chance of survival (Arrese and Soulages 2009; Kajita and Evans 2010; Beukeboom 2018). These results 386 are consistent with arguments for maintaining semi-natural habitats, diversifying cropping systems, and 387 increasing the number of edges (e.g., by reducing the size of fields) in agricultural landscapes where 388 conservation of beneficial arthropods such as lady beetles and their ecosystem services are desirable. 


\section{DECLARATIONS}

$390 \quad$ Funding

391 This research was supported by the United States Department of Agriculture (USDA) grants 2011-67009-

39230022 and 2018-67013-28060 to CG.

393 Conflicts of interest

394 The authors declare no conflict of interest.

395 Ethics approval

396 None required.

397 Consent to participate

398 None required.

399 Consent for publication

400 All authors agree to the content of this manuscript.

401 DATA AVAILABILITY

402 Data is available in Online Supplement 2.

403 CODE AVAILABILITY

404 Code is available in Online Supplement 2.

\section{AUTHORS' CONTRIBUTIONS}

406 JT and CG conceived of the study. JT conducted field sampling and laboratory analysis. BI and JT analyzed

407 the data. BI wrote the first manuscript draft. All authors contributed to subsequent drafts. 


\section{REFERENCES}

Alaux C, Allier F, Decourtye A, et al (2017) A 'Landscape physiology' approach for assessing bee health highlights the benefits of floral landscape enrichment and semi-natural habitats. Sci Rep 7:. https://doi.org/10.1038/srep40568

Anderson JME (1981) Seasonal Field Analyses of Fat Content, Live Weight, Dry Weight and Water Content of the Aphidophagous Scymnodes Lividigaster (Mulsant) and Mycophagous Leptothea Galbula (Mulsant) (Coleoptera: Coccinellidae). Aust J Zool 29:679-689. https://doi.org/10.1071/zo9810679

Arrese EL, Soulages JL (2009) Insect fat body: energy, metabolism, and regulation. Annu Rev Entomol 55:207-225. https://doi.org/10.1146/annurev-ento-112408-085356

Bahlai CA, Colunga-Garcia M, Gage SH, Landis DA (2015) The role of exotic ladybeetles in the decline of native ladybeetle populations: evidence from long-term monitoring. Biol Invasions 17:10051024. https://doi.org/10.1007/s10530-014-0772-4

Berkvens N, Bonte J, Berkvens D, et al (2008) Influence of diet and photoperiod on development and reproduction of European populations of Harmonia axyridis (Pallas)(Coleoptera: Coccinellidae). Biol Control Invasion Ladybird Harmon Axyridis Model Species 211-221

Bertrand C, Eckerter PW, Ammann L, et al (2019) Seasonal shifts and complementary use of pollen sources by two bees, a lacewing and a ladybeetle species in European agricultural landscapes. J Appl Ecol 56:2431-2442. https://doi.org/10.1111/1365-2664.13483

Beukeboom LW (2018) Size matters in insects - an introduction. Entomol Exp Appl 166:2-3. https://doi.org/10.1111/eea.12646

Bommarco R (1998) Reproduction and Energy Reserves of a Predatory Carabid Beetle Relative to Agroecosystem Complexity. Ecol Appl 8:846-853. https://doi.org/10.1890/10510761(1998)008[0846:RAEROA]2.0.CO;2

Bonte D, Van Dyck H, Bullock JM, et al (2012) Costs of dispersal. Biol Rev 87:290-312. https://doi.org/10.1111/j.1469-185X.2011.00201.x

Brooks ME, Kristensen K, Benthem KJ van, et al (2017) glmmTMB Balances Speed and Flexibility Among Packages for Zero-inflated Generalized Linear Mixed Modeling. R J 9:378-400

Brown PMJ, Roy HE (2018) Native ladybird decline caused by the invasive harlequin ladybird Harmonia axyridis: evidence from a long-term field study. Insect Conserv Divers 11:230-239. https://doi.org/10.1111/icad.12266

Chaplin-Kramer R, O'Rourke ME, Blitzer EJ, Kremen C (2011) A meta-analysis of crop pest and natural enemy response to landscape complexity. Ecol Lett 14:922-932. https://doi.org/10.1111/j.14610248.2011.01642.x

Clough Y, Kruess A, Tscharntke T (2007) Local and landscape factors in differently managed arable fields affect the insect herbivore community of a non-crop plant species. J Appl Ecol 44:22-28. https://doi.org/10.1111/j.1365-2664.2006.01239.x 
Cooke SJ, Sack L, Franklin CE, et al (2013) What is conservation physiology? Perspectives on an increasingly integrated and essential science. Conserv Physiol 1:. https://doi.org/10.1093/conphys/cot001

Dainese M, Martin EA, Aizen MA, et al (2019) A global synthesis reveals biodiversity-mediated benefits for crop production. Sci Adv 5:eaax0121. https://doi.org/10.1126/sciadv.aax0121

Delignette-Muller ML, Dutang C (2015) fitdistrplus: An R Package for Fitting Distributions. J Stat Softw 64:1-34. https://doi.org/10.18637/jss.v064.i04

Diepenbrock LM, Finke DL (2013) Refuge for native lady beetles (Coccinellidae) in perennial grassland habitats. Insect Conserv Divers 6:671-679. https://doi.org/10.1111/icad.12027

Dolezal AG, Clair ALS, Zhang G, et al (2019) Native habitat mitigates feast-famine conditions faced by honey bees in an agricultural landscape. Proc Natl Acad Sci 116:25147-25155. https://doi.org/10.1073/pnas.1912801116

Drapela T, Frank T, Heer X, et al (2013) Landscape structure affects activity density, body size and fecundity of Pardosa wolf spiders (Araneae: Lycosidae) in winter oilseed rape. EJE 108:609-614. https://doi.org/10.14411/eje.2011.079

Dunning JB, Danielson BJ, Pulliam HR (1992) Ecological processes that affect populations in complex landscapes. Oikos 65:169-175. https://doi.org/10.2307/3544901

Ellis RD, McWhorter TJ, Maron M (2012) Integrating landscape ecology and conservation physiology. Landsc Ecol 27:1-12. https://doi.org/10.1007/s10980-011-9671-6

Evans EW (2003) Searching and reproductive behaviour of female aphidophagous ladybirds (Coleoptera: Coccinellidae): a review. EJE 100:1-10. https://doi.org/10.14411/eje.2003.001

Fahrig L (2007) Non-optimal animal movement in human-altered landscapes. Funct Ecol 21:1003-1015. https://doi.org/10.1111/j.1365-2435.2007.01326.x

Fox J, Weisberg S (2018) An R Companion to Applied Regression. SAGE Publications

Gámez-Virués S, Perović DJ, Gossner MM, et al (2015) Landscape simplification filters species traits and drives biotic homogenization. Nat Commun 6:. https://doi.org/10.1038/ncomms9568

Gardiner MA, Tuell JK, Isaacs R, et al (2010) Implications of Three Biofuel Crops for Beneficial Arthropods in Agricultural Landscapes. BioEnergy Res 3:6-19. https://doi.org/10.1007/s12155009-9065-7

Gardiner MM, Landis DA, Gratton C, et al (2009a) Landscape diversity enhances biological control of an introduced crop pest in the north-central USA. Ecol Appl 19:143-154. https://doi.org/10.1890/071265.1

Gardiner MM, Landis DA, Gratton C, et al (2009b) Landscape composition influences patterns of native and exotic lady beetle abundance. Divers Distrib 15:554-564. https://doi.org/10.1111/j.14724642.2009.00563.x 
505

506

Gardiner MM, O’Neal ME, Landis DA (2011) Intraguild Predation and Native Lady Beetle Decline. PLOS ONE 6:e23576. https://doi.org/10.1371/journal.pone.0023576

Grab H, Brokaw J, Anderson E, et al (2019) Habitat enhancements rescue bee body size from the negative effects of landscape simplification. J Appl Ecol 56:2144-2154. https://doi.org/10.1111/13652664.13456

Grez AA, Rand TA, Zaviezo T, Castillo-Serey F (2013) Land use intensification differentially benefits alien over native predators in agricultural landscape mosaics. Divers Distrib 19:749-759. https://doi.org/10.1111/ddi.12027

Grez AA, Zaviezo T, Hernández J, et al (2014) The heterogeneity and composition of agricultural landscapes influence native and exotic coccinellids in alfalfa fields. Agric For Entomol 16:382390. https://doi.org/10.1111/afe.12068

Guerra C, Aráoz E (2016) Amphibian malformations and body condition across an agricultural landscape of northwest Argentina. Dis Aquat Organ 121:105-116. https://doi.org/10.3354/dao03048

Hadley, AS, \& Betts, MG (2016) Refocusing habitat fragmentation research using lessons from the last decade. Current Landscape Ecology Reports, 1(2), 55- 66. https://doi.org/10.1007/s40823-0160007-8

Harmon JP, Stephens E, Losey J (2007) The decline of native coccinellids (Coleoptera: Coccinellidae) in the United States and Canada. J Insect Conserv 11:85-94. https://doi.org/10.1007/s10841-0069021-1

Harwood J, Phillips S, Anderson J, et al (2009) Invertebrate biodiversity affects predator fitness and hence potential to control pests in crops. Biol Control 51:499-506. https://doi.org/10.1016/j.biocontrol.2009.09.007

Hemberger J, Crossley MS, Gratton C (2021) Historical decrease in agricultural landscape diversity is associated with shifts in bumble bee species occurrence. Ecol Lett 24:1800-1813. https://doi.org/10.1111/ele.13786

Hesselbarth MHK, Sciaini M, With KA, et al (2019) landscapemetrics: an open-source R tool to calculate landscape metrics. Ecography 42:1648-1657. https://doi.org/10.1111/ecog.04617

Hodek I (1973) Biology of Coccinellidae. Dr. W. Junk N.V., The Hague

Hodek I, Iperti G, Hodkova M (1993) Long-distance flights in Coccinellidae (Coleoptera). EJE 90:403414

Iuliano B, Gratton C (2020) Temporal resource (dis)continuity for conservation biological control: from field to landscape scales. Front Sustain Food Syst 4.. https://doi.org/10.3389/fsufs.2020.00127

Jonsen ID, Fahrig L (1997) Response of generalist and specialist insect herbivores to landscape spatial structure. Landsc Ecol 12:185-197. https://doi.org/10.1023/A:1007961006232

Kajita Y, Evans EW (2010) Relationships of body size, fecundity, and invasion success among predatory lady beetles (Coleoptera: Coccinellidae) inhabiting alfalfa fields. Ann Entomol Soc Am 103:750756. https://doi.org/10.1603/AN10071 
Knapp M, Knappová J (2013) Measurement of body condition in a common carabid beetle, Poecilus cupreus: a comparison of fresh weight, dry weight, and fat content. J Insect Sci 13:. https://doi.org/10.1673/031.013.0601

Koh, I, Rowe, HI, \& Holland, JD. (2013). Graph and circuit theory connectivity models of conservation biological control agents. Ecological Applications, 23(7), 1554-1573. https://doi.org/10.1890/121595.1

Kuussaari M, Bommarco R, Heikkinen RK, et al (2009) Extinction debt: a challenge for biodiversity conservation. Trends Ecol Evol 24:564-571. https://doi.org/10.1016/j.tree.2009.04.011

Lamb RJ, Bannerman JA, Costamagna AC (2019) Stability of native and exotic lady beetle populations in a diverse landscape. Ecosphere 10:e2630. https://doi.org/10.1002/ecs2.2630

Latimer CE, Smith OM, Taylor JM, et al (2020) Landscape context mediates the physiological stress response of birds to farmland diversification. J Appl Ecol 57:671-680. https://doi.org/10.1111/1365-2664.13583

Le Provost G, Thiele J, Westphal C, et al (2021) Contrasting responses of above- and belowground diversity to multiple components of land-use intensity. Nat Commun 12:3918. https://doi.org/10.1038/s41467-021-23931-1

Lease HM, Wolf BO (2011) Lipid content of terrestrial arthropods in relation to body size, phylogeny, ontogeny and sex. Physiol Entomol 36:29-38. https://doi.org/10.1111/j.1365-3032.2010.00767.x

Liere H, Kim TN, Werling BP, et al (2015) Trophic cascades in agricultural landscapes: indirect effects of landscape composition on crop yield. Ecol Appl 25:652-661. https://doi.org/10.1890/14-0570.1

Lundgren JG, Wiedenmann RN (2004) Nutritional suitability of corn pollen for the predator Coleomegilla maculata (Coleoptera: Coccinellidae). J Insect Physiol 50:567-575. https://doi.org/10.1016/j.jinsphys.2004.04.003

Macé OG, Ebeling A, Eisenhauer N, et al (2019) Variations in trophic niches of generalist predators with plant community composition as indicated by stable isotopes and fatty acids. SOIL Org 91:45-59. https://doi.org/10.25674/so91204

Mancini F, Woodcock BA, Redhead J, et al (2020) Chapter Three - Detecting landscape scale consequences of insecticide use on invertebrate communities. In: Bohan DA, Vanbergen AJ (eds) Advances in Ecological Research. Academic Press, pp 93-126

Marques RV, Sarmento RA, Lemos F, et al (2015) Active prey mixing as an explanation for polyphagy in predatory arthropods: synergistic dietary effects on egg production despite a behavioural cost. Funct Ecol 29:1317-1324. https://doi.org/10.1111/1365-2435.12439

Martin EA, Dainese M, Clough Y, et al (2019) The interplay of landscape composition and configuration: new pathways to manage functional biodiversity and agroecosystem services across Europe. Ecol Lett 22:1083-1094. https://doi.org/10.1111/ele.13265

McGarigal K (1995) FRAGSTATS: Spatial Pattern Analysis Program for Quantifying Landscape Structure. U.S. Department of Agriculture, Forest Service, Pacific Northwest Research Station 
Meehan, TD, Werling, BP, Landis, DA, \& Gratton, C (2011) Agricultural landscape simplification and insecticide use in the Midwestern United States. Proceedings of the National Academy of Sciences, 108(28):11500-11505. https://doi-org/10.1073/pnas.1100751108

Mogren CL, Benítez M-S, McCarter K, et al (2020) Diverging landscape impacts on macronutrient status despite overlapping diets in managed (Apis mellifera) and native (Melissodes desponsa) bees. Conserv Physiol 8:. https://doi.org/10.1093/conphys/coaa109

Morita A, Soga K, Hoson T, et al (1999) Changes in mechanical properties of the cuticle and lipid accumulation in relation to adult diapause in the bean bug, Riptortus clavatus. J Insect Physiol 45:241-247. https://doi.org/10.1016/S0022-1910(98)00119-X

Nieuwenhuis R, Grotenhuis M te, Pelzer B (2017) Weighted Effect Coding for Observational Data with wec. R J 9:477-485

Öberg S (2009) Influence of landscape structure and farming practice on body condition and fecundity of wolf spiders. Basic Appl Ecol 10:614-621. https://doi.org/10.1016/j.baae.2009.03.005

Obrycki JJ, Harwood JD, Kring TJ, O’Neil RJ (2009) Aphidophagy by Coccinellidae: application of biological control in agroecosystems. Biol Control 51:244-254. https://doi.org/10.1016/j.biocontrol.2009.05.009

Östman Ö (2005) Asynchronous temporal variation among sites in condition of two carabid species. Ecol Entomol 30:63-69. https://doi.org/10.1111/j.0307-6946.2005.00661.x

Östman Ö, Ekbom B, Bengtsson J, Weibull A-C (2001) Landscape Complexity and Farming Practice Influence the Condition of Polyphagous Carabid Beetles. Ecol Appl 11:480-488. https://doi.org/10.1890/1051-0761(2001)011[0480:LCAFPI]2.0.CO;2

Pinheiro J, Bates D, DebRoy S, Sarkar D (2021) nlme: Linear and Nonlinear Mixed Effects Models. https://cran.r-project.org/web/packages/nlme/nlme.pdf. Accessed 4 Nov 2021

Plaistow S, Siva-Jothy MT (1996) Energetic constraints and male mate-securing tactics in the damselfly Calopteryx splendens xanthostoma (Charpentier). Proc R Soc Lond B Biol Sci 263:1233-1239. https://doi.org/10.1098/rspb.1996.0181

Rand TA, Tylianakis JM, Tscharntke T (2006) Spillover edge effects: the dispersal of agriculturally subsidized insect natural enemies into adjacent natural habitats. Ecol Lett 9:603-614. https://doi.org/10.1111/j.1461-0248.2006.00911.x

Raubenheimer D, Mayntz D, Simpson SJ, Tøft S (2007) Nutrient-Specific Compensation Following Diapause in a Predator: Implications for Intraguild Predation. Ecology 88:2598-2608. https://doi.org/10.1890/07-0012.1

Renauld M, Hutchinson A, Loeb G, et al (2016) Landscape Simplification Constrains Adult Size in a Native Ground-Nesting Bee. PLOS ONE 11:e0150946. https://doi.org/10.1371/journal.pone.0150946

Rusch A, Chaplin-Kramer R, Gardiner MM, et al (2016) Agricultural landscape simplification reduces natural pest control: A quantitative synthesis. Agric Ecosyst Environ 221:198-204. https://doi.org/10.1016/j.agee.2016.01.039 
Salomão RP, González-Tokman D, Dáttilo W, et al (2018) Landscape structure and composition define the body condition of dung beetles (Coleoptera: Scarabaeinae) in a fragmented tropical rainforest. Ecol Indic 88:144-151. https://doi.org/10.1016/j.ecolind.2018.01.033

Santos KFA, Zanuzo Zanardi O, de Morais MR, et al (2017) The impact of six insecticides commonly used in control of agricultural pests on the generalist predator Hippodamia convergens (Coleoptera: Coccinellidae). Chemosphere 186:218-226. https://doi.org/10.1016/j.chemosphere.2017.07.165

Schellhorn NA, Bianchi FJJA, Hsu CL (2014) Movement of Entomophagous Arthropods in Agricultural Landscapes: Links to Pest Suppression. Annu Rev Entomol 59:559-581. https://doi.org/10.1146/annurev-ento-011613-161952

Seibold S, Gossner MM, Simons NK, et al (2019) Arthropod decline in grasslands and forests is associated with landscape-level drivers. Nature 574:671-674. https://doi.org/10.1038/s41586-019-1684-3

Simpson EH (1949) Measurement of Diversity. Nature 163:688-688. https://doi.org/10.1038/163688a0

Soares AO, Coderre D, Schanderl H (2004) Dietary self-selection behaviour by the adults of the aphidophagous ladybeetle Harmonia axyridis (Coleoptera: Coccinellidae). J Anim Ecol 73:478486. https://doi.org/10.1111/j.0021-8790.2004.00822.x

Specty O, Febvay G, Grenier S, et al (2003) Nutritional plasticity of the predatory ladybeetle Harmonia axyridis (Coleoptera: Coccinellidae): Comparison between natural and substitution prey. Arch Insect Biochem Physiol 52:81-91. https://doi.org/10.1002/arch.10070

Staudacher K, Rennstam Rubbmark O, Birkhofer K, et al (2018) Habitat heterogeneity induces rapid changes in the feeding behaviour of generalist arthropod predators. Funct Ecol 32:809-819. https://doi.org/10.1111/1365-2435.13028

Stowe HE, Michaud JP, Kim T (2021a) The Benefits of Omnivory for Reproduction and Life History of a Specialized Aphid Predator, Hippodamia convergens (Coleoptera: Coccinellidae). Environ Entomol 50:69-75. https://doi.org/10.1093/ee/nvaa154

Stowe HE, Michaud JP, Kim TN (2021b) Floral Resources Enhance Fecundity, but Not Flight Activity, in a Specialized Aphid Predator, Hippodamia convergens (Coleoptera: Coccinellidae). Front Ecol Evol 9:619. https://doi.org/10.3389/fevo.2021.748870

Stuligross C, Williams NM (2021) Past insecticide exposure reduces bee reproduction and population growth rate. PNAS 118:np. https://doi.org/10.1073/pnas.2109909118

te Grotenhuis M, Pelzer B, Eisinga R, et al (2017) When size matters: advantages of weighted effect coding in observational studies. Int J Public Health 62:163-167. https://doi.org/10.1007/s00038-0160901-1

Tiede J, Scherber C, Mutschler J, et al (2017) Gut microbiomes of mobile predators vary with landscape context and species identity. Ecol Evol 7:8545-8557. https://doi.org/10.1002/ece3.3390

Tiede J, Wemheuer B, Traugott M, et al (2016) Trophic and Non-Trophic Interactions in a Biodiversity Experiment Assessed by Next-Generation Sequencing. PLOS ONE 11:e0148781. https://doi.org/10.1371/journal.pone.0148781 
645

646

652

653

654

Tscharntke T, Tylianakis JM, Rand TA, et al (2012) Landscape moderation of biodiversity patterns and processes - eight hypotheses. Biol Rev 87:661-685. https://doi.org/10.1111/j.1469185X.2011.00216.X

Vargas G, Michaud JP, Nechols JR (2012) Larval Food Supply Constrains Female Reproductive Schedules in Hippodamia convergens (Coleoptera: Coccinellidae). Ann Entomol Soc Am 105:832839. https://doi.org/10.1603/AN12010

Vargas G, Michaud JP, Nechols JR (2013a) Cryptic maternal effects in Hippodamia convergens vary with maternal age and body size. Entomol Exp Appl 146:302-311. https://doi.org/10.1111/eea.12027

Vargas G, Michaud JP, Nechols JR (2013b) Trajectories of Reproductive Effort in Coleomegilla maculata and Hippodamia convergens (Coleoptera: Coccinellidae) Respond to Variation in Both Income and Capital. Environ Entomol 42:341-353. https://doi.org/10.1603/EN12191

Werling BP, Meehan TD, Gratton C, Landis DA (2011) Influence of habitat and landscape perenniality on insect natural enemies in three candidate biofuel crops. Biol Control 59:304-312. https://doi.org/10.1016/j.biocontrol.2011.06.014

Wickham H (2016) ggplot2: Elegant Graphics for Data Analysis. https://ggplot2.tidyverse.org. Accessed 4 Nov 2021

Wilder SM, Raubenheimer D, Simpson SJ (2016) Moving beyond body condition indices as an estimate of fitness in ecological and evolutionary studies. Funct Ecol 30:108-115. https://doi.org/10.1111/1365-2435.12460

Woltz JM, Landis DA (2014) Coccinellid response to landscape composition and configuration. Agric For Entomol 16:341-349. https://doi.org/10.1111/afe.12064

Yang L, Xu L, Liu B, et al (2019) Non-crop habitats promote the abundance of predatory ladybeetles in maize fields in the agricultural landscape of northern China. Agric Ecosyst Environ 277:44-52. https://doi.org/10.1016/j.agee.2019.03.008

Yang L, Zeng Y, Xu L, et al (2018) Change in ladybeetle abundance and biological control of wheat aphids over time in agricultural landscape. Agric Ecosyst Environ 255:102-110. https://doi.org/10.1016/j.agee.2017.12.013 
656 Fig. 1 Location of the 30 sites (black points) sampled across the state of Wisconsin from April to September 657 2011. Inset maps show examples of $1 \mathrm{~km}$ buffers around the sampling locations with the corresponding land cover classification based on USDA data.

Fig. 2 Effect of landscape predictors (\% intensive cropland, landscape diversity, and edge density) on lady beetle body condition (body size, body density, and lipid content). The x-axis shows standardized (z-scored) beta coefficients of the specific landscape predictors in linear mixed effects models. Black diamonds represent the overall effect of the landscape predictor on the body condition metric. Colored dots represent

663 species-specific effects, whose estimates were calculated from interaction terms between landscape 664 predictor and species. Error bars represent 95\% confidence intervals. Filled symbols and lines highlight 665 confidence intervals that do not cross the zero line, representing significant landscape effects. All species666 specific confidence intervals overlap with confidence intervals for the overall effect, indicating that there 667 were no species for which the relationship between body condition and landscape metric was statistically 668 different from the all-species mean (see also Online Supplement S1).

669 Fig. 3 Effect of landscape predictors within $1 \mathrm{~km}$ of sampling locations on the body condition metrics of 670 lady beetles, presented as partial residual plots (back-transformed from ln-transformation for illustrative 671 purposes). The panels show: (a) the relationship between the amount of intensive cropland and body 672 density; (b) the relationship between habitat edge and body density; (c) the relationship between the amount 673 of intensive cropland and lipid content; (d) the relationship between landscape diversity and body density.

674 Species-specific effects (individual lines) are shown for illustrative purposes only; the interaction between 675 landscape metrics and lady beetle species was not significant in any model (see also Table 2 and Online 676 Supplement Table S1). 
677 Table 1. Overview of the five lady beetle species collected, their origin and body condition

678 metrics (mean and standard deviation SD) with number of individuals (n) analyzed for each.

\begin{tabular}{|c|c|c|c|c|}
\hline Species (origin) & Body condition metric & $\mathbf{n}$ & mean & SD \\
\hline \multirow{4}{*}{$\begin{array}{l}\text { Coleomegilla maculata, De Geer } \\
\text { (native) }\end{array}$} & Size index $\left(\mathrm{mm}^{2}\right)$ & 559 & 8.92 & 1.22 \\
\hline & Density $\left(\mathrm{mg} / \mathrm{mm}^{2}\right)$ & 544 & 0.47 & 0.09 \\
\hline & Lipid content & 558 & 28.75 & 7.06 \\
\hline & Egg presence & 83 & - & - \\
\hline \multirow{4}{*}{$\begin{array}{l}\text { Harmonia axyridis, Pallas } \\
\text { (non-native) }\end{array}$} & Size index $\left(\mathrm{mm}^{2}\right)$ & 486 & 16.61 & 2.25 \\
\hline & Density $\left(\mathrm{mg} / \mathrm{mm}^{2}\right)$ & 415 & 0.71 & 0.13 \\
\hline & Lipid content & 486 & 31.92 & 10.29 \\
\hline & Egg presence & 247 & - & - \\
\hline \multirow{4}{*}{$\begin{array}{l}\text { Cycloneda munda, Say } \\
\text { (native) }\end{array}$} & Size index $\left(\mathrm{mm}^{2}\right)$ & 114 & 9.61 & 1.35 \\
\hline & Density $\left(\mathrm{mg} / \mathrm{mm}^{2}\right)$ & 113 & 0.46 & 0.10 \\
\hline & Lipid content & 114 & 27.43 & 7.02 \\
\hline & Egg presence & 32 & - & - \\
\hline \multirow{4}{*}{$\begin{array}{l}\text { Coccinella septempunctata, L. } \\
\text { (non-native) }\end{array}$} & Size index $\left(\mathrm{mm}^{2}\right)$ & 65 & 19.01 & 2.85 \\
\hline & Density $\left(\mathrm{mg} / \mathrm{mm}^{2}\right)$ & 65 & 0.67 & 0.20 \\
\hline & Lipid content & - & - & - \\
\hline & Egg presence & 51 & - & - \\
\hline \multirow{4}{*}{$\begin{array}{l}\text { Hippodamia variegata, Goeze } \\
\text { (non-native) }\end{array}$} & Size index $\left(\mathrm{mm}^{2}\right)$ & 58 & 6.85 & 1.04 \\
\hline & Density $\left(\mathrm{mg} / \mathrm{mm}^{2}\right)$ & 52 & 0.42 & 0.10 \\
\hline & Lipid content & 58 & 31.92 & 7.16 \\
\hline & Egg presence & - & - & - \\
\hline
\end{tabular}


Table 2. Summary of landscape effects on lady beetle body condition.

\begin{tabular}{|c|c|c|c|c|c|c|c|c|c|}
\hline \multirow{2}{*}{ Explanatory variables } & \multicolumn{3}{|c|}{ Body size } & \multicolumn{3}{|c|}{ In (Body density) } & \multicolumn{3}{|c|}{ In (Lipid content) } \\
\hline & $\chi^{2}$ & df & $P(>\chi 2)$ & $\chi^{2}$ & df & $\mathbf{P}(>\chi 2)$ & $\chi^{2}$ & df & $P(>\chi 2)$ \\
\hline \multicolumn{10}{|c|}{ \% Intensive cropland models } \\
\hline Intens. cropland & 1.0 & 1 & 0.318 & 4.4 & 1 & 0.036 & 4.6 & 1 & 0.032 \\
\hline Species & 1987.7 & 4 & $<0.001$ & 460.0 & 4 & $<0.001$ & 27.1 & 3 & $<0.001$ \\
\hline Date & 1.0 & 1 & 0.318 & 16.2 & 2 & $<0.001$ & 5.0 & 2 & 0.081 \\
\hline Intens. cropland:Species & 5.4 & 4 & 0.250 & 4.2 & 4 & 0.373 & 1.78 & 3 & 0.641 \\
\hline Date:Species & 4.5 & 4 & 0.337 & 46.6 & 8 & $<0.001$ & 118.9 & 6 & $<0.001$ \\
\hline \multicolumn{10}{|l|}{ Landscape diversity models } \\
\hline Landsc. diversity & 0.5 & 1 & 0.471 & 0.4 & 1 & 0.518 & 0.7 & 1 & 0.401 \\
\hline Species & 1883.0 & 4 & $<0.001$ & 488.6 & 4 & $<0.001$ & 24.8 & 3 & $<0.001$ \\
\hline Date & 1.4 & 1 & 0.239 & 18.4 & 2 & $<0.001$ & 4.8 & 2 & 0.093 \\
\hline Landsc. diversity:Species & 1.3 & 4 & 0.861 & 6.3 & 4 & 0.188 & 4.8 & 3 & 0.185 \\
\hline Date:Species & 5.0 & 4 & 0.283 & 49.6 & 8 & $<0.001$ & 122.0 & 6 & $<0.001$ \\
\hline \multicolumn{10}{|l|}{ Edge density models } \\
\hline Edge density & 1.3 & 1 & 0.260 & 2.9 & 1 & 0.087 & 1.1 & 1 & 0.292 \\
\hline Species & 2038.4 & 4 & $<0.001$ & 509.6 & 4 & $<0.001$ & 27.9 & 3 & $<0.001$ \\
\hline Date & 1.7 & 4 & 0.203 & 18.4 & 2 & $<0.001$ & 5.5 & 2 & 0.063 \\
\hline Edge density:Species & 1.6 & 4 & 0.811 & 5.8 & 4 & 0.213 & 0.5 & 3 & 0.925 \\
\hline Date:Species & 4.9 & 4 & 0.300 & 49.1 & 8 & $<0.001$ & 120.4 & 6 & $<0.001$ \\
\hline
\end{tabular}

681 Results of linear mixed-effects models testing the effects of landscape predictors (\% intensive cropland,

682 landscape diversity, edge density), beetle species and collection date (in the body density and lipid content

683 models, a quadratic term was used for collection date) on body condition metrics (body size, ln-transformed

684 body density and ln-transformed lipid content) of coccinellids. Test statistics are based on type II Wald chi-

685 square tests at $\alpha=0.05 . P$ values $<0.05$ are reported in bold numbers and $P<0.10$ in italics. The

686 corresponding coefficients of variation, standard errors, and $P$ values for taxon contrasts are reported in the

687 Online Supplement Table S1. Abbreviations: $d f=$ degrees of freedom. 


\section{Figures}

\section{Figure 1}

Location of the 30 sites (black points) sampled across the state of Wisconsin from April to September 2011. Inset maps show examples of $1 \mathrm{~km}$ buffers around the sampling locations with the corresponding land cover classification based on USDA data.

\section{Figure 2}

Effect of landscape predictors (\% intensive cropland, landscape diversity, and edge density) on lady beetle body condition (body size, body density, and lipid content). The x-axis shows standardized (zscored) beta coefficients of the specific landscape predictors in linear mixed effects models. Black diamonds

represent the overall effect of the landscape predictor on the body condition metric. Colored dots represent species-specific effects, whose estimates were calculated from interaction terms between landscape predictor and species. Error bars represent $95 \%$ confidence intervals. Filled symbols and lines highlight confidence intervals that do not cross the zero line, representing significant landscape effects. All species666 specific confidence intervals overlap with confidence intervals for the overall effect, indicating that there

were no species for which the relationship between body condition and landscape metric was statistically different from the all-species mean (see also Online Supplement S1).

\section{Figure 3}

Effect of landscape predictors within $1 \mathrm{~km}$ of sampling locations on the body condition metrics of lady beetles, presented as partial residual plots (back-transformed from In-transformation for illustrative purposes). The panels show: (a) the relationship between the amount of intensive cropland and body

density; (b) the relationship between habitat edge and body density; (c) the relationship between the amount of intensive cropland and lipid content; (d) the relationship between landscape diversity and body density. Species-specific effects (individual lines) are shown for illustrative purposes only; the interaction between landscape metrics and lady beetle species was not significant in any model (see also Table 2 and Online Supplement Table S1) 


\section{Supplementary Files}

This is a list of supplementary files associated with this preprint. Click to download.

- Tiedeetalsupplementalmaterial.pdf

- beetle.data.csv

- beetle.data.with.metadata.xlsx

- landscape.data.csv

- landscape.data.with.metadata.xlsx

- tiede2022code.rmd 